\title{
$\begin{array}{r}\text { WAGENINGEN } \\ \text { UNIVERSITY \& RESEARCH } \\ \hline\end{array}$
}

\section{Spatial variation of carbon and nutrients stocks in Amazonian Dark Earth}

Brazao Vieira Alho, C. F., Samuel Rosa, A., Coimbra Martins, G., Hiemstra, T., Kuijper, T. W. M., \& Teixeira, W. G.

This is a "Post-Print" accepted manuscript, which has been published in "Geoderma"

This version is distributed under a non-commercial no derivatives Creative Commons (c) $(\mathcal{\Theta \Theta} \Theta$ (CC-BY-NC-ND) user license, which permits use, distribution, and reproduction in any medium, provided the original work is properly cited and not used for commercial purposes. Further, the restriction applies that if you remix, transform, or build upon the material, you may not distribute the modified material.

Please cite this publication as follows:

Brazao Vieira Alho, C. F., Samuel Rosa, A., Coimbra Martins, G., Hiemstra, T., Kuijper, T. W. M., \& Teixeira, W. G. (2019). Spatial variation of carbon and nutrients stocks in Amazonian Dark Earth. Geoderma, 337, 322-332. DOI: 10.1016/j.geoderma.2018.09.040

You can download the published version at:

https://doi.org/10.1016/i.geoderma.2018.09.040 


\section{Spatial variation of carbon and nutrients stocks in Amazonian Dark Earth}

Carlos Francisco Brazão Vieira Alho ${ }^{\mathrm{a},{ }^{*}}$, Alessandro Samuel-Rosa ${ }^{\mathrm{b}}$, Gilvan Coimbra Martins $^{c}$, Tjisse Hiemstra ${ }^{a}$, Thomas W. Kuypera ${ }^{a}$, Wenceslau Geraldes Teixeira ${ }^{d}$

a Department of Soil Quality, Wageningen University \& Research, 6700 AA, Wageningen, the Netherlands.

${ }^{b}$ Federal University of Technology - Paraná, 85892-000, Santa Helena, Brazil.

c Embrapa Western Amazon, 69010-970, Manaus, Brazil.

d Embrapa Soils, 22460-000, Rio de Janeiro, Brazil.

\section{Abstract}

Amazonian Dark Earths (ADE) are anthropic soils that are enriched in carbon (C) and several nutrients, particularly calcium $(\mathrm{Ca})$ and phosphorus $(\mathrm{P})$, when compared to adjacent soils from the Amazon basin. Studies on ADE empower the understanding of complex pre-Columbian cultural development in the Amazon and may also provide insights for future sustainable agricultural practices in the tropics. ADE are highly variable in size, depth and soil physico-chemical characteristics. Nonetheless, the differentiation between $A D E$ and the adjacent soils is not standardized and is commonly done based on visual field observations. In this regard, the pretic horizon has been recently proposed as an attempt to classify ADE systematically. Spatial modelling techniques can be of great use to study the structure of the spatial variation of soil properties in highly variable areas. Here, we predicted the carbon and nutrients stocks in ADE by applying spatial modelling techniques using an environmental covariate (i.e. expected anthropic enrichment gradient) in our model. In addition, we used the pretic horizon criteria to classify pretic and non-pretic areas and evaluate their relative contribution to the total stocks. In this study, we collected soil samples from five $20-\mathrm{cm}$ soil layers at $n=53$ georeferenced points placed in a grid of about 10 to $60 \mathrm{~m}$ spacing in a study area located in Central Amazon ( 9.4 ha). Ceramic fragments were weighed and quantified. Samples were analysed for: Total $\mathrm{C}$, Total $\mathrm{Ca}$, Total $\mathrm{P}$, Exchangeable $\mathrm{Ca}$ $+\mathrm{Mg}$, Extractable $\mathrm{P}$, soil $\mathrm{pH}$, potential CEC $(\mathrm{pH}=7.0)$ and the clay content. The use of the pretic horizon criteria allowed us to clearly distinguish two unambiguous areas with a sharp transition, rather than a smooth continuum, in contrast to previous studies in ADE. Depth- and profile-wise linear regression model parameters indicated a greater importance of the chosen environmental covariate (i.e. expected anthropic enrichment gradient) to explain the spatial variation of Total $\mathrm{Ca}$ and Total $\mathrm{P}$ stocks than Total $\mathrm{C}$ stocks. The overall Total $\mathrm{Ca}$ and Total $\mathrm{P}$ stocks were twice as large in the pretic area when compared to the non-pretic area.

\section{Highlights}

- Carbon and nutrients stocks in ADE were predicted using an environmental covariate.

- Total $\mathrm{Ca}$ and Total P contents exhibited better fit to our model than Total C content.

- Pretic horizon criteria enabled the differentiation of two unambiguous areas.

- Pretic relative contribution was higher for Total $\mathrm{Ca}$ and Total $\mathrm{P}$ than Total $\mathrm{C}$ stocks. 


\section{Keywords}

Amazonian Dark Earths; Spatial modelling; Carbon stocks; Nutrients stocks; Pretic horizon

\section{Introduction}

Amazonian Dark Earths (ADE) are anthropic soils (Anthrosols) characterized by darker colour and enrichment in carbon $(\mathrm{C})$ and other nutrients, particularly calcium (Ca) and phosphorus (P). These soils also exhibit higher $\mathrm{pH}$ and cation exchange capacity (CEC) and frequently evidences of human activity (e.g. ceramic artefacts and charcoal fragments) when compared to the carbon- and nutrient-poor adjacent soils from the Amazon basin (Glaser et al., 2001; Kämpf et al., 2003; Kern et al., 2017; Sombroek, 1966). Radiocarbon dating indicated that these soils were formed between 2500 and 500 before present and are of pre-Columbian origin (Neves et al., 2003). Possible carbon and nutrients sources are: terrestrial/aquatic plant biomass, human/animal excrements/bones and charcoal/ash residues of incomplete combustion (Glaser, 2007).

Due to the prevalence of weathered clay minerals (e.g. kaolinite) and iron and aluminium oxides in these soils, their ability to retain nutrients depends mainly on soil organic matter (SOM). However, high temperature and precipitation in the tropics accelerate the decomposition of SOM. Studies have suggested that high carbon content in ADE are related to the black carbon (BC) content in these soils (Glaser, 2007; Glaser et al., 2001). BC has been claimed to be one of the most stable forms of carbon found in soils due to its poly-condensed aromatic structure that makes it more difficult to be decomposed by soil microorganisms (Glaser, 2007; Haumaier and Zech, 1995; Novotny et al., 2007). In addition, high CEC in ADE is also likely to increase primary production due to higher soil fertility. Therefore, SOM input of non$\mathrm{BC}$ origin is also expected to be increased in ADE. Despite tropical conditions, ADE have intriguingly remained highly fertile after abandonment of sites following European colonization. Current research indicates that the extent and intensity with which Amerindians occupied and transformed the Amazon is far more complex than previously assumed due to possible environmental limitations (Kern et al., 2017). Studies on ADE empower the understanding of complex pre-Columbian cultural development in the Amazon and may also provide insights for future sustainable agricultural practices in the tropics.

ADE are highly variable in size, depth and soil physico-chemical characteristics not only among different sites, but also within a single site. This variation is mainly caused by the diversity and complexity of pre-Columbian settlements (Costa et al., 2013; Costa and Kern, 1999; Kern et al., 2015). The debate whether ADE were formed intentionally (for agricultural purposes) or unintentionally (as the unintended consequence of waste deposition), seems to be diminishing in relevance. Currently, scientists tend to perceive the formation of ADE (and other Anthrosols) as the inevitable outcome of daily activities throughout years of past human occupations (Fraser et al., 2014). The persistence of anthropic markers likely depends on frequency and intensity of occupation of the site that may lead to a regime shift which manifests as ADE formation (Browne-Ribeiro, 2016).

The differentiation between ADE and the adjacent soil is commonly done by nonquantitative field observations based on soil colour and the presence of 
archaeological remains (i.e. ceramic and charcoal fragments). Costa et al. (2013) reported that ADE characteristics could fit several qualifiers for Anthrosols. Recently, the pretic horizon has been proposed as an attempt to classify ADE systematically and better accommodate ADE within Anthrosols (IUSS Working Group WRB, 2015). This is important because it takes into consideration quantitative data rather than vague descriptive data. The pretic horizon is a dark surface horizon that among other criteria is characterized by high contents of carbon and nutrients.

Geochemical signatures reflect the variation within and beyond the limits of anthropic areas that were previously defined by visual evidence. Schmidt et al. (2014) reported a widespread pattern of past human occupation where terraces of domestic areas (e.g. houses or yards) are surrounded by waste disposal areas as middens that build up into mounds over time. Different geochemical signatures can be linked to past land use and occupation (Costa et al., 2013). However, interpretation of these patterns may be hindered by site-inherent complexity of past settlements and current land use and occupation (Kern et al., 2015). Moreover, anthropic soils likely exhibit these complexities both in small- and large-scale analyses. Hence, we still lack a solid understanding of the specific mechanisms that led to the formation and diversity of ADE (Schmidt et al., 2014). Limited and localized soil sampling is unlikely to elucidate those mechanisms in highly variable areas.

Spatial modelling techniques can be of great use to study the structure of the spatial variation of soil properties as it considers the continuity of spatial phenomena and the deterministic effect of environmental conditions. For soil scientists, it is a great tool to visualize how soil properties can vary greatly both horizontally and vertically. For archaeologists, it is a great tool to infer on the location of specific activities in the past. Significant progress in spatial modelling techniques was possible due to recent advances in data processing. However, several methodological hurdles are still evident, especially in large areas with high spatial variation between soil properties and environmental covariates (Song et al., 2016). These hurdles can be of great importance in anthropic areas where abrupt and gradual transitions can be expected horizontally and vertically due to the complexity of settlements. Therefore, it is important to include uncertainties of predictions when using these techniques.

Correlation between soil variables is not only dependent on the distance between sampling points, but also on their location. Therefore, environmental conditions may show a trend across a study area. Stochastic simulation of spatially distributed soil properties can be used for better predictions as it preserves the structure of the spatial variation, whereas kriging usually smoothens (Heuvelink and Webster, 2001). Predictions may be improved by using exhaustive environmental covariates (Lark and Webster, 2006). However, including several covariates is not always related to an increase in prediction accuracy (Samuel-Rosa et al., 2015).

Therefore, the aims of this study were to: (i) predict the Total C, Total $\mathrm{Ca}$ and Total $P$ stocks using an environmental covariate (including the uncertainties of predictions) and (ii) use the pretic horizon criteria to classify pretic and non-pretic areas and evaluate their relative contribution to the total stocks.

\section{Material and Methods}

\subsection{Study area}


The study area ( 9.4 ha) is situated on the north margin of the Solimões river (Amazon river), in the municipality of Iranduba, Amazonas state, Brazil (0314'22" 031547" S and 601'ㅇ'- 601350" W) (Fig. 1). Regional climate is classified as Aw according to Köppen classification (tropical rainy). Local annual mean temperature is $26.7^{\circ} \mathrm{C}$, annual mean rainfall is $2100 \mathrm{~mm}$ and relative humidity is about $80 \%$. The local slope is flat to undulated and the site is located above existing watercourses. The most common soil classes in the region are Xanthic Ferralsols, Plinthic Ferralsols, Pisoplinthic Plinthosols and Xanthic Acrisols (Macedo et al., 2017). The study area is locally known as the Experimental Research Station of Caldeirão - Embrapa Western Amazon. Part of the study area ( 30\%), located in the west (W) and southwest (SW) sectors, is composed of a forested area that has not been cultivated for over 40 years. The remaining part ( 70\%), was converted into an experimental field where several crops have been cultivated and soil management practices have been applied over the past 40 years.

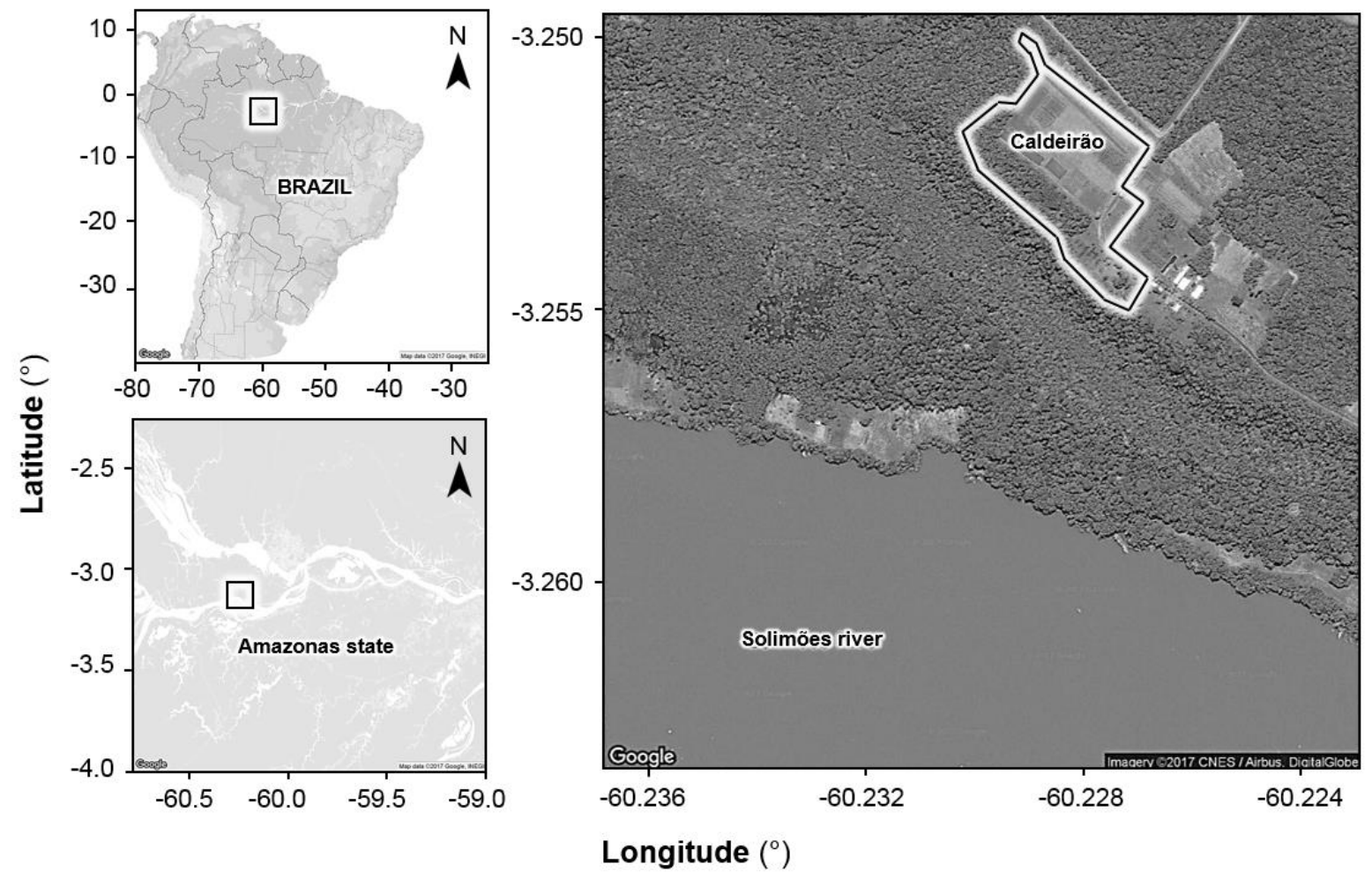

Fig. 1. Location of the study area (Experimental Research Station of Caldeirão Embrapa Western Amazon). (Google Earth $®$ images).

\subsection{Soil sampling and analysis}

Soil samples were collected from five $20-\mathrm{cm}$ soil layers (from 0 to $100 \mathrm{~cm}$ ) with a manual post hole digger (sample volume $=0.0063 \mathrm{~m}^{3}$ ) at $\mathrm{n}=53$ georeferenced points ( $\sim 5 \mathrm{~m}$ horizontal precision) placed in a grid of about 10 to $60 \mathrm{~m}$ spacing (265 soil samples). Ceramic fragments $(>2 \mathrm{~mm}$ ) were weighed and quantified. Samples were air-dried, sieved through $2 \mathrm{~mm}$ mesh, homogenized and stored in plastic bags at room temperature prior to analyses. Samples were analysed for: Total C, Total $\mathrm{Ca}$, Total $\mathrm{P}$, Exchangeable $\mathrm{Ca}+\mathrm{Mg}$, Extractable $\mathrm{P}$, soil $\mathrm{pH}$, potential $\mathrm{CEC}($ at $\mathrm{pH}=$ 7.0) and clay content. Total $C$ was determined using an elemental analyser (PerkinElmer 2400 Series II) where acetanilide was used as reference material. Total $\mathrm{Ca}$ and Total $\mathrm{P}$ were determined at Geosol laboratories by Inductively Coupled 
Plasma-Optical Emission Spectrometry (ICP-OES), where samples were previously digested with a multi-acid solution $\left(\mathrm{HCl}, \mathrm{HNO}_{3}, \mathrm{HF}\right.$ and $\left.\mathrm{HClO}_{4}\right)$. Extractable $\mathrm{P}, \mathrm{K}, \mathrm{Na}$ (Mehlich 1), Exchangeable $\mathrm{Ca}+\mathrm{Mg}(1 \mathrm{M} \mathrm{KCl})$ and $\mathrm{H}+\mathrm{Al}(0.5 \mathrm{M}$ calcium acetate at $\mathrm{pH}$ 7.0) were also determined. Soil $\mathrm{pH}$ was determined in water (soil:water ratio of 1:2.5), potential $\mathrm{CEC}$ (at $\mathrm{pH}=7.0$ ) was defined as the sum of exchangeable cations $(\mathrm{K}, \mathrm{Na}, \mathrm{Ca}+\mathrm{Mg})$ plus acidity $(\mathrm{H}+\mathrm{Al})$ and the clay content was determined by the pipet method after organic matter removal with hydrogen peroxide. Detailed description on the methods are described in Embrapa (2017).

\subsection{Spatial modelling}

The spatial variation of soil properties was modelled as a function of fixed (deterministic) and random (stochastic) effects. The fixed effects describe the part of the spatial variation of a soil property that can be explained using spatially exhaustive covariates (Heuvelink and Webster, 2001). Spatial data covering the entire study area that can be related to the environmental conditions that likely influenced the observed large-scale patterns of spatial variation ( $>50 \mathrm{~m}$ in our study area) can be used as covariates. Here, we assumed that past anthropic activities that caused enrichment of carbon and nutrients likely occurred closer to the river, despite specificity among activities. In addition, the current land use in the SW sector (forested area) is also expected to have caused some enrichment of organic matter due to SOM input, whereas the current land use in the NE (agronomic experimental field) is expected to have caused some impoverishment of organic matter due to cultivation. Therefore, the largest enrichment of carbon and nutrients likely occurred in the SW sector with decreasing enrichment gradient towards the NE sector. Because of the spatial association between these conditions, we chose to use one covariate to serve as their surrogate, which we defined as the expected anthropic enrichment gradient (Fig. 2a).

The understanding that this covariate could explain the large-scale spatial variation of soil properties was formalised by individually calibrating depth-wise linear regression models with soil property as dependent variable and the covariate as the independent variable. For an arbitrary soil depth $(d)$, such linear regression model was defined as:

$$
Y(\boldsymbol{s} i, d)=\beta_{0 d}+\exp \left[\boldsymbol{x}\left(\boldsymbol{s}_{i}, d\right)\right]^{\top} \beta_{1 d}+\varepsilon\left(\boldsymbol{s}_{i}, d\right) \text {, with } i=1,2, \ldots, n,
$$

where the $\beta$ 's are the estimated linear regression model coefficients conditional on the soil property $(Y)$ and the covariate data $(\boldsymbol{x})$ at the observation locations $(\boldsymbol{s} i, d)$. The covariate is expressed in exponential form to emphasise the combined effect of past and current land use and occupation on enrichment of carbon and nutrients nearby the margin of the river.

In Eq. (1), $\varepsilon\left(\boldsymbol{s}_{i}, d\right)$ is the spatially auto-correlated difference between the fitted and observed values of the soil property (regression residuals) (Heuvelink and Webster, 2001). For an arbitrary soil depth (d), the structure of this spatial autocorrelation was analysed using the auto-variogram:

$Y_{d}(\boldsymbol{h})=0.5 \operatorname{mean}\left\{\left[\varepsilon\left(\boldsymbol{s}_{i}, d\right)-\varepsilon\left(\boldsymbol{s}_{i}+\boldsymbol{h}, d\right)\right]^{2}\right\}$

where $\boldsymbol{h}$ is a vector of separation distances between two observation locations ( $\boldsymbol{s}_{i}$ and $\left.\boldsymbol{s}_{i}+\boldsymbol{h}\right)$. We used five exponentially spaced distance classes up to a maximum 
separation distance of about $315 \mathrm{~m}$ (half the diagonal of study area). Exponentially spaced distance classes were used because they deliver a better picture of the small-scale structure of spatial variation $(<50 \mathrm{~m}$ in our study area) (Pettitt and McBratney, 1993). The size of the two smallest distance classes ( 20 m) starting at the variogram origin was determined by the sampling grid spacing ( 10 to $60 \mathrm{~m}$ ).

Regression residuals of a soil property from adjacent soil depths can be expected to have the same magnitude and/or sign. Such vertical correlation is characterized by the translocation of elements from upper to lower soil depths caused by natural and/or anthropic influences. For any two arbitrary soil depths, $d_{j}$ and $d_{k}$, the structure of this spatial cross-correlation was analysed using the cross-variogram (Kyriakidis and Journel, 1999).

$V_{j k}(\boldsymbol{h})=0.5 \operatorname{mean}\left\{\left[\varepsilon\left(\boldsymbol{s}_{i}, d_{j}\right)-\varepsilon\left(\boldsymbol{s}_{i}+\boldsymbol{h}, d_{j}\right)\right]\left[\varepsilon\left(\boldsymbol{s}_{i}, d_{k}\right)-\varepsilon\left(\boldsymbol{s}_{i}+\boldsymbol{h}, d_{k}\right)\right]\right\}$, with $j \neq k$

By using the cross-variogram, we enforced the depth-wise auto-variograms of a soil property to be coherent among soil depths. For all soil properties, the shape of the variograms was defined using the sum of a nugget variance and the exponential covariance function:

$\gamma(\boldsymbol{h})=c_{0}+c[1-\exp (-\boldsymbol{h} / 0.333 a)]$

where $c_{0}$ is the nugget variance, $c$ is the sill variance, and $a$ is the correlation range (Supplementary Data).

Considering the phenomenon under study and the scale of analysis determined by the range of distances between nearest neighbouring observations ( 10 to $60 \mathrm{~m}$ ), the choice for using the exponential covariance function reflects our expectation that the spatial auto- and cross-correlation decrease rapidly with increasing separation distances. Generally, the nugget variance arises from measurements errors and very small-scale spatial variation. In this study, the latter corresponds to separation distances smaller than about $35 \mathrm{~m}$ (average distance between nearest-neighbouring observations).

The depth-wise empirical distribution of soil properties was transformed to Gaussian using the Box-Cox family of power transformations to meet statistical constraints and facilitate the estimation of model parameters. Then, the Box-Cox transformed variables were standardized to zero mean and unit standard deviation. The parameters of the depth-wise linear regression models were estimated using ordinary least squares, while the parameters of the auto- and cross-variogram models were estimated using iteratively reweighted least squares within the framework of the linear model of coregionalization (Pebesma, 2004).

For Total $\mathrm{C}$, Total $\mathrm{Ca}$ and Total $\mathrm{P}$, universal cokriging was used to make spatial predictions of the contents. Predicted values and prediction error variances were back-transformed using simulations as described elsewhere (Samuel-Rosa et al., 2015). For Total $\mathrm{C}$, Exchangeable $\mathrm{Ca}+\mathrm{Mg}$ and Extractable $\mathrm{P}$ data at the first depth $(0-20 \mathrm{~cm})$ used for the pretic horizon criteria, conditional sequential Gaussian simulation was used to produce 1000 equally probable realisations of their respective random fields (Pebesma, 2004). Spatial predictions and simulations were done in regular grids per soil depth containing 94,462 point-predictions at $1.0 \mathrm{~m}$ spacing. For further information on the geostatistical methods we used here, we refer to Goovaerts (1997) and Webster and Oliver (2007). 


\subsection{Computation of predicted carbon and nutrients stocks}

Point-predicted values of Total C, Total $\mathrm{Ca}$ and Total $\mathrm{P}$ contents were taken to be equivalent to the average content of the respective element expected to be found in blocks of $0.2 \mathrm{~m}^{3}$. This was possible since point and block universal cokriging should yield equivalent predictions given the existing sampling density and the chosen prediction grid spacing. Then, the risk of underestimating the true prediction errors is minimized since block kriging yields lower estimates of the prediction error variance than point kriging (Oliver and Webster, 2014).

Although it is often reported that $A D E$ are rich in ceramic fragments, quantitative data is rarely shown. Therefore, the relative contribution of ceramics volume to the total soil volume is often unknown. In our study area, the volume of coarse fragments (i.e. ceramics fragments) per volume of soil was generally below $1 \%$ and never larger than $4 \%$. In fact, ceramics were absent in $65 \%$ of our soil samples (Fig. $2 b$ ). Therefore, the volume of coarse fragments was assumed to be negligible and was not included to estimate the stocks.

Data on soil bulk density were obtained from three soil profiles located in our study area (P1, P2 and P3 in Fig. 2a) and described in previous studies (Macedo, 2012; Neves Júnior, 2008). These data could not be readily used as the soil depths intervals did not match the $20-\mathrm{cm}$ soil layers of our study. Therefore, we fitted a model to the soil bulk density data using the depth at the centre of the sampled soil layers as predictor variable. To account for nonlinearities in the relation between soil bulk density and soil depth, the latter was transformed into $m$ sets of new variables using natural spline basis functions (Hastie et al., 2009). These consisted of $m$ cubic polynomial functions fitted to $m$ adjacent subsets of the soil depth data, each subset being defined by breakpoints (knots) at the appropriate $m-1$ percentiles. The collection of polynomial functions was constrained to be continuous at the inner knots and linear beyond the boundary knots. Based on leave-one-out crossvalidation results (data not shown), we found the best number of degrees of freedom of the natural cubic spline (the number of piecewise polynomials) to be $m=5$. The fitted model was used to predict soil bulk density at the centre of the five $20-\mathrm{cm}$ soil layers (i.e. 10, 30, 50, 70, and $90 \mathrm{~cm}$ ) (Fig. 2c). Predicted values were then assumed to be equivalent to the average soil bulk density of the respective depths throughout the entire study area. 

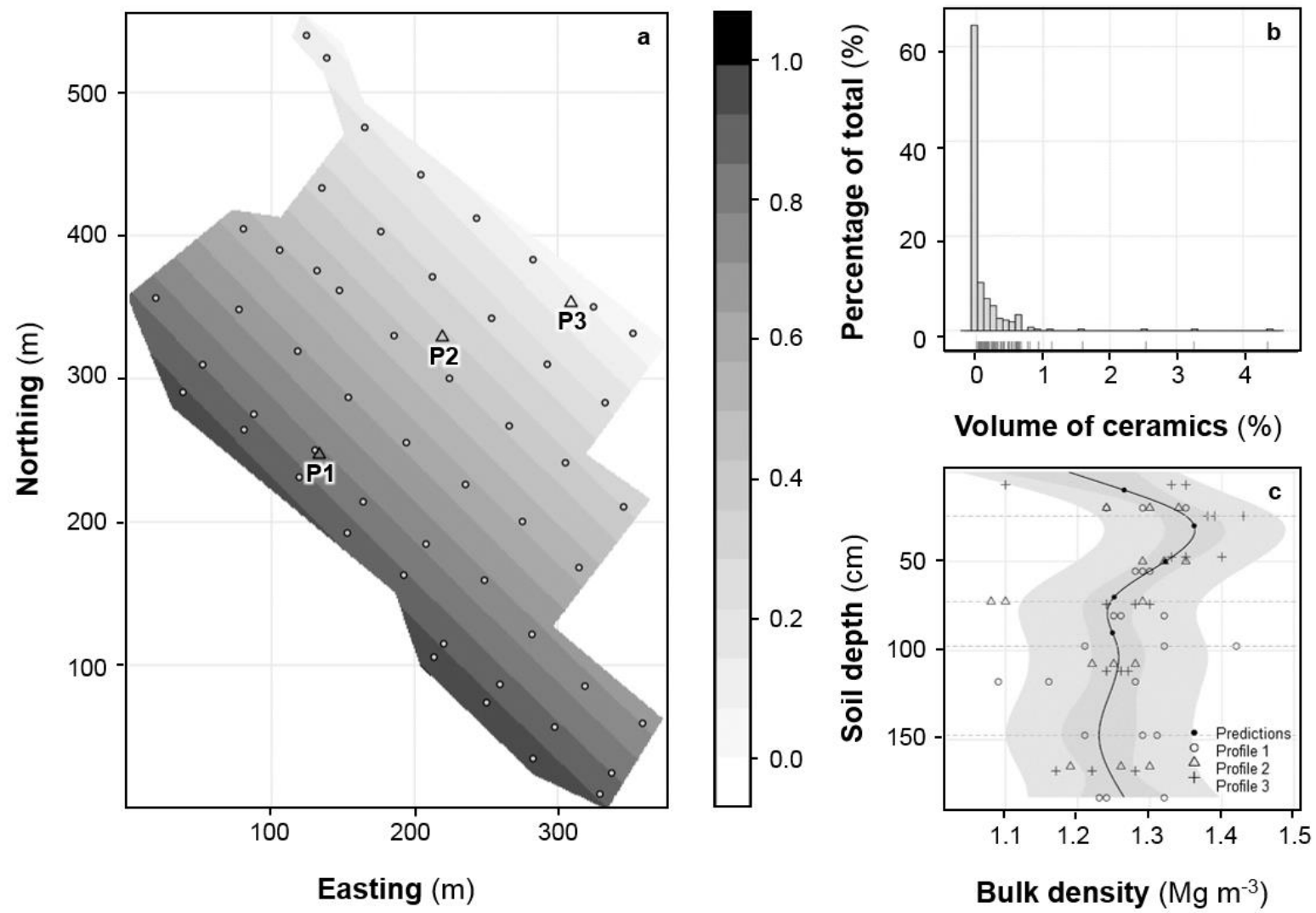

Fig. 2. (a) Expected anthropic enrichment gradient (covariate). Values range linearly from 0 to 1 , where 1 means maximum enrichment. The location of the $n=53$ sampling points and the three soil profiles (P1, P2 and P3) used to model soil bulk density are indicated as circles and triangles, respectively. (b) Frequency distribution of the volume of ceramics to the total volume of soil. (c) Soil bulk density modelled as a function of soil depth. The $90 \%$ confidence and prediction intervals around the fitted natural spline are shown in dark and light grey, respectively. Horizontal dashed lines indicate the position of the interior knots of the natural cubic spline.

Depth-wise predictions of Total $\mathrm{C}$, Total $\mathrm{Ca}$ and Total $\mathrm{P}$ stocks $\left(\mathrm{kg} \mathrm{m}^{-2}\right)$ were done by multiplying the predicted contents $\left(\mathrm{g} \mathrm{kg}^{-1}\right)$ to the predicted soil bulk density $\left(\mathrm{BD}, \mathrm{Mg} \mathrm{m}^{-3}\right)$ and the known thickness of the soil layer $(0.2 \mathrm{~m})$. Depth-wise uncertainty of predicted stocks was approximated using a straightforward first-order Taylor series expansion (Heuvelink et al., 1989). For instance, the standard deviation $(\sigma)$ of a total stock in an arbitrary block of $0.2 \mathrm{~m}^{3}$ was calculated as:

$\sigma_{\text {stock }} \approx 0.2 \cdot\left(\mathrm{BD}^{2} \cdot \sigma^{2} \text { content }+ \text { content }^{2} \cdot \sigma^{2} \mathrm{BD}\right)^{0.5}$

Profile-wise prediction of the stocks $\left(\mathrm{kg} \mathrm{m}^{-2}\right)$ was done by stacking all five depthwise predictions and then computing the combined stocks in blocks of $1.0 \mathrm{~m}^{3}$. Profile-wise uncertainty of predicted stocks was approximated by squaring the standard deviation $(\sigma)$ of each of the $0.2 \mathrm{~m}^{3}$ stacked blocks, computing the sum and taking the square root of that value.

\subsection{Classification of pretic and non-pretic areas}


The pretic horizon, among other diagnostic criteria, is a dark surface horizon with one or more layers with a combined thickness of $\geq 20 \mathrm{~cm}$, that has: (i) $\geq 10 \mathrm{~g} \mathrm{~kg}^{-1}$ Organic carbon; (ii) $\geq 2 \mathrm{cmol}_{\mathrm{c} \mathrm{kg}}{ }^{-1}$ Exchangeable $\mathrm{Ca}+\mathrm{Mg}$ and (iii) $\geq 30 \mathrm{mg} \mathrm{kg}^{-1}$ Extractable P (IUSS Working Group WRB, 2015). Here, we compute the probability of these three soil properties at the first soil depth $(0-20 \mathrm{~cm})$ to meet the diagnostic criteria by accounting the number of time the pretic horizon criteria were met in 1000 simulations at each of the 94,462 points of the simulation grid. The three probabilities were multiplied and the value was taken as the estimated pretic probability (pretic). Finally, a cut-off at $p_{\text {pretic }} \geq 0.9$ was used to differentiate pretic from non-pretic areas. Total C, Total $\mathrm{Ca}$ and Total $\mathrm{P}$ stocks on each area were then computed separately to evaluate the relative contribution of pretic and non-pretic areas to the total stocks.

\section{Results}

\subsection{Soil properties}

Depth-wise empirical distribution of soil properties is shown in Fig. 3. Total C, Total $\mathrm{Ca}$ and CEC exhibited a trend to decrease with soil depth, as well as their variation, although the distribution remained skewed. Total $\mathrm{P}$ and $\mathrm{pH}$ remained approximately constant with soil depth. However, the variance of Total P increased with soil depth, as well as its skewness. The variance of $\mathrm{pH}$ exhibited an approximately symmetric distribution. The clay content increased with soil depth with approximately constant variance and symmetric distribution.

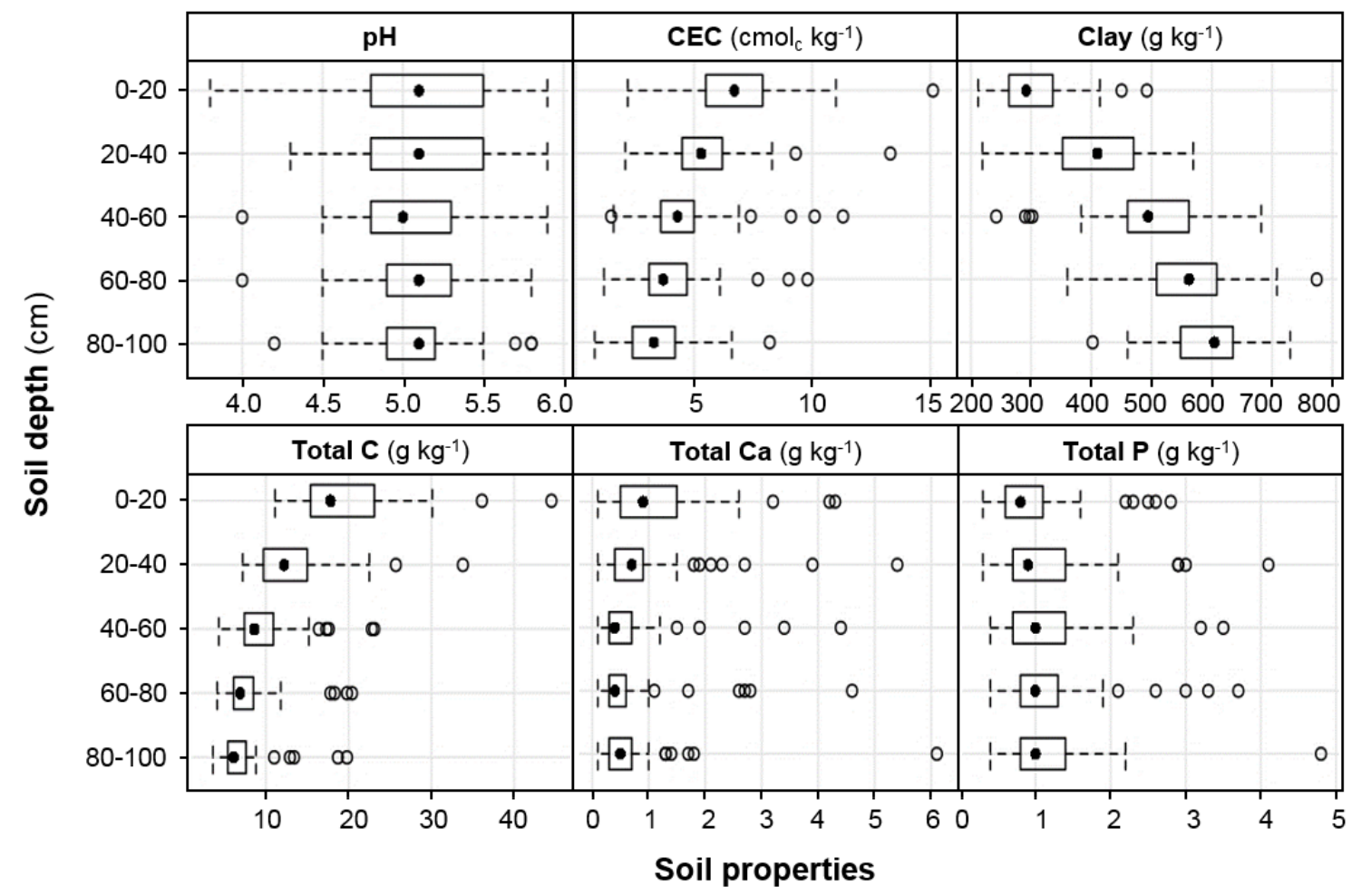

Fig. 3. Depth-wise empirical distribution of Total C, Total Ca, Total P, potential CEC (at $\mathrm{pH}=7.0$ ), $\mathrm{pH}$ and clay content (Clay) in $\mathrm{n}=53$ observation locations at five 20$\mathrm{cm}$ soil layers (265 soil samples). The filled black dot in each box-and-whisker plot represents the median or second quartile (0.5), while the box range indicates the first and third quartiles $(0.25,0.75)$ defining the interquartile interval. The whisker length 
represents data points that are not distant from the box $\geq 1.5$ times the box length, while the empty circles indicate extreme values.

\subsection{Linear regression model parameters}

Estimated depth-wise linear regression model parameters are shown in Table 1. The amount of variance explained given by the coefficients of determination $\left(R^{2}\right)$ was overall low $(0.01$ to 0.34$)$. Out of the three elements, Total $C$ had the lowest $R^{2}$ values $(0.01$ to 0.08$)$ and the data fit to the model was not significant in all soil depths $(p>0.05)$. Compared to Total $C$, Total $\mathrm{Ca}$ had slightly higher $\mathrm{R}^{2}$ values $(0.07$ to 0.24$)$ and Total $P$ had the highest $R^{2}$ values $(0.24$ to 0.34$)$. Total $C a$ and $P$ data fit to the model was significant in all soil depths $(p<0.05)$, except for Total $\mathrm{Ca}$ at 80 $100 \mathrm{~cm}(p>0.05)$.

Table 1. Depth-wise linear regression model coefficients fitted to Total $\mathrm{C}$, Total $\mathrm{Ca}$ and Total $P$ and the amount of variance explained by the covariate as measured with the regression sum of squares and the coefficient of determination $\left(R^{2}\right)$.

\begin{tabular}{lllrrr}
\hline Soil depth $(\mathrm{cm})$ & Intercept & Covariate & Sum of Squares & $\mathbf{R}^{\mathbf{2}}$ & $\boldsymbol{p}$ \\
\hline Total C & & & & & \\
0-20 & $-0.99(0.51)$ & $0.54(0.26)$ & 3.91 & 0.08 & 0.05 \\
$20-40$ & $-0.78(0.51)$ & $0.42(0.27)$ & 2.44 & 0.05 & 0.12 \\
$40-60$ & $-0.67(0.52)$ & $0.36(0.27)$ & 1.79 & 0.03 & 0.18 \\
$60-80$ & $-0.40(0.52)$ & $0.22(0.27)$ & 0.65 & 0.01 & 0.43 \\
$80-100$ & $-0.28(0.52)$ & $0.15(0.27)$ & 0.30 & 0.01 & 0.59
\end{tabular}

\section{Total Ca}

$0-20$

20-40

40-60

60-80

$80-100$

$\begin{array}{ll}-1.77(0.46) & 0.96(0.24) \\ -1.47(0.48) & 0.79(0.25) \\ -1.62(0.47) & 0.87(0.25) \\ -1.60(0.47) & 0.86(0.25) \\ -0.96(0.51) & 0.52(0.26)\end{array}$

\section{Total P}

$0-20$

20-40

40-60

$60-80$

80-100
$-1.79(0.46)$

$-1.97(0.44)$

$-2.11(0.43)$

$-2.07(0.43)$

$-1.91(0.45)$
$0.97(0.24)$

$1.07(0.23)$

$1.14(0.22)$

$1.12(0.23)$

$1.03(0.23)$

$\begin{array}{rrr}12.36 & 0.24 & 0.00 \\ 8.52 & 0.16 & 0.00 \\ 10.36 & 0.20 & 0.00 \\ 10.12 & 0.19 & 0.00 \\ 3.64 & 0.07 & 0.06\end{array}$

$\begin{array}{lll}12.68 & 0.24 & 0.00\end{array}$

$\begin{array}{lll}15.43 & 0.30 & 0.00\end{array}$

$\begin{array}{lll}17.64 & 0.34 & 0.00\end{array}$

$\begin{array}{lll}16.94 & 0.33 & 0.00\end{array}$

$\begin{array}{lll}14.45 & 0.28 & 0.00\end{array}$

Data were Box-Cox transformed and standardized to zero mean and unit standard deviation prior to analysis. The approximate standard errors of the fitted coefficients are shown in brackets. The $p$ values of the $F$ statistics indicate the approximate significance of the covariate.

\subsection{Predicted carbon and nutrients stocks}

Depth- and profile-wise maps of predicted Total C, Total Ca and Total P stocks and maps of the associated standard deviation of predictions are shown in Fig. 4, Fig. 5 and Fig. 6, respectively. Stocks are commonly reported in $\mathrm{Mg} \mathrm{ha}^{-1}$ for a certain soil depth. Here, given the point-prediction spacing $(1.0 \mathrm{~m})$, stocks are reported in $\mathrm{kg}$ $\mathrm{m}^{-2}$ in depth- $(0.2 \mathrm{~m})$ and profile-wise $(1.0 \mathrm{~m})$ maps. 
Depth-wise maps of predicted Total C, Total $\mathrm{Ca}$ and Total P stocks indicated enrichments in the SW sector that decrease gradually with soil depth. One patch in the SW sector exhibited the highest Total C stocks $\left(\sim 10.0 \mathrm{~kg} \mathrm{~m}^{-2}\right)$ in the uppermost soil layer $(0-20 \mathrm{~cm})$. This evidence fades down to $40-60 \mathrm{~cm}$ soil depth $\left(\sim 4.0 \mathrm{~kg} \mathrm{~m}^{-2}\right)$ and diffuses linearly in the NE direction. The Total $\mathrm{C}$ stocks in the last two soil depths $(60-80$ and $80-100 \mathrm{~cm})$ were rather homogenous $\left(\sim 1.0\right.$ to $\left.3.0 \mathrm{~kg} \mathrm{~m}^{-2}\right)$ for the entire study area (Fig. 4a). Large patches enriched in Ca $\left(\sim 0.8 \mathrm{~kg} \mathrm{~m}^{-2}\right)$ were identified in the uppermost soil layer $(0-20 \mathrm{~cm})$. This evidence fades down with soil depth while diffusing in the NE direction. The Total Ca stocks were up to $\sim 0.5 \mathrm{~kg} \mathrm{~m}^{-2}$ even at the lowest soil layer $(80-100 \mathrm{~cm})$ (Fig. 5a). The patches with the highest Total $\mathrm{C}$ and Total Ca stocks diffusing from the SW to the NE sector, can also be seen on the maps of predicted Total P stocks. The highest Total P stocks $\left(\sim 1.0 \mathrm{~kg} \mathrm{~m}^{-}\right.$ $\left.{ }^{2}\right)$ were found in subsurface layers $(20-40$ and $40-60 \mathrm{~cm})$. Nonetheless, Total $P$ stocks were up to $0.6 \mathrm{~kg} \mathrm{~m}^{-2}$ even at the lowest soil layer $(80-100 \mathrm{~cm})$ (Fig. 6a). Profile-wise maps of predicted Total C, Total $\mathrm{Ca}$ and Total $\mathrm{P}$ stocks emphasized the highest stocks in the SW sector as well as the enrichment gradient that diffuses in the NE direction (Fig. 4c, Fig. 5c and Fig. 6c). Depth- (Fig. 4b, Fig. 5b and Fig. 6b) and profile-wise (Fig. 4d, Fig. 5d and Fig. 6d) maps of associated standard deviation of predictions showed that uncertainties were higher in the SW sector given the extreme values found in this part of the study area. 

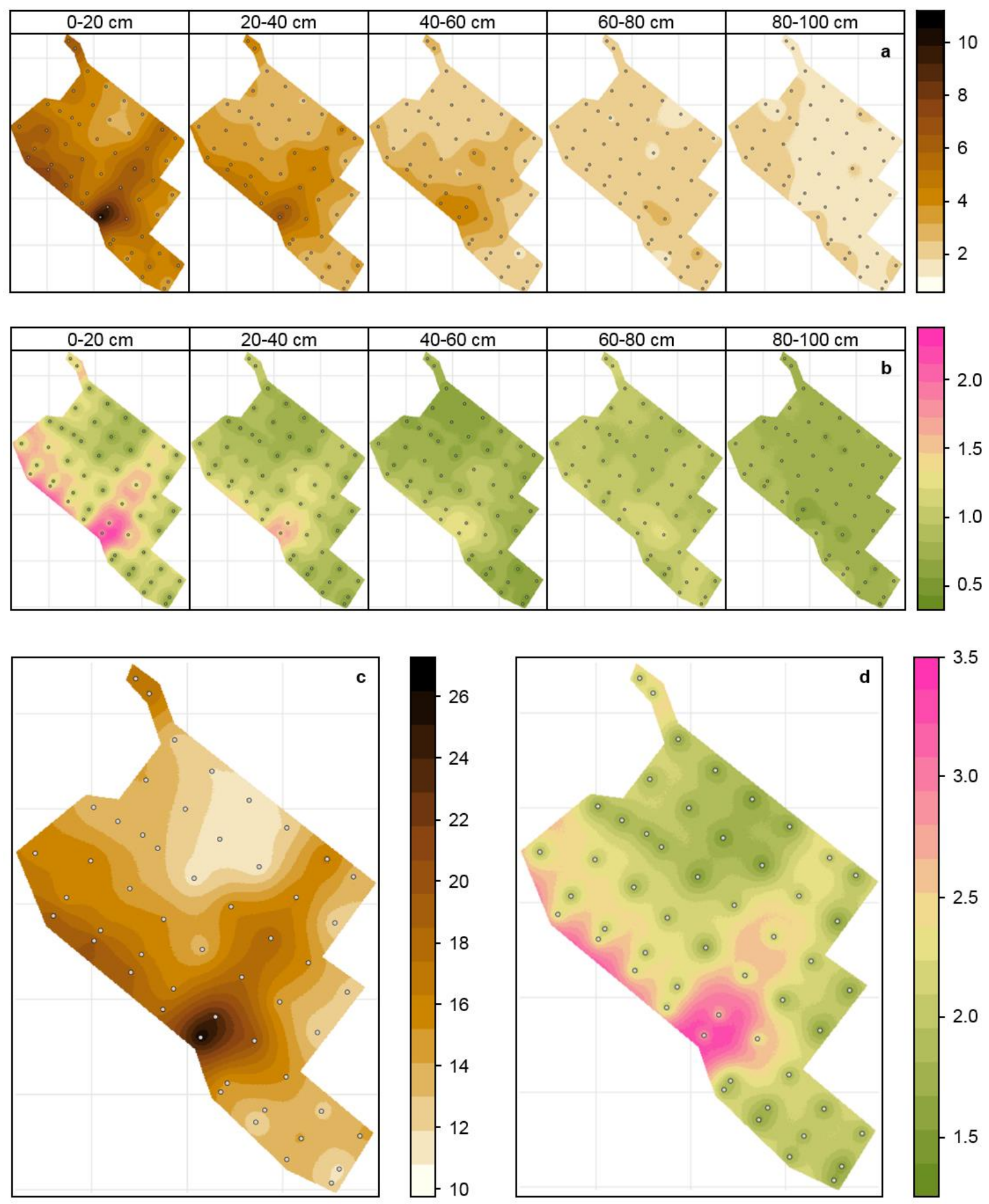

Fig. 4. Depth- $(0.2 \mathrm{~m})$ and profile-wise $(1.0 \mathrm{~m})$ maps of predicted Total $\mathrm{C}$ stocks $(\mathrm{kg}$ $\mathrm{m}^{-2}$ ) (a and $\mathrm{c}$, respectively) including the maps of the associated standard deviation $\left(\mathrm{kg} \mathrm{m}^{-2}\right)$ (b and d, respectively). 

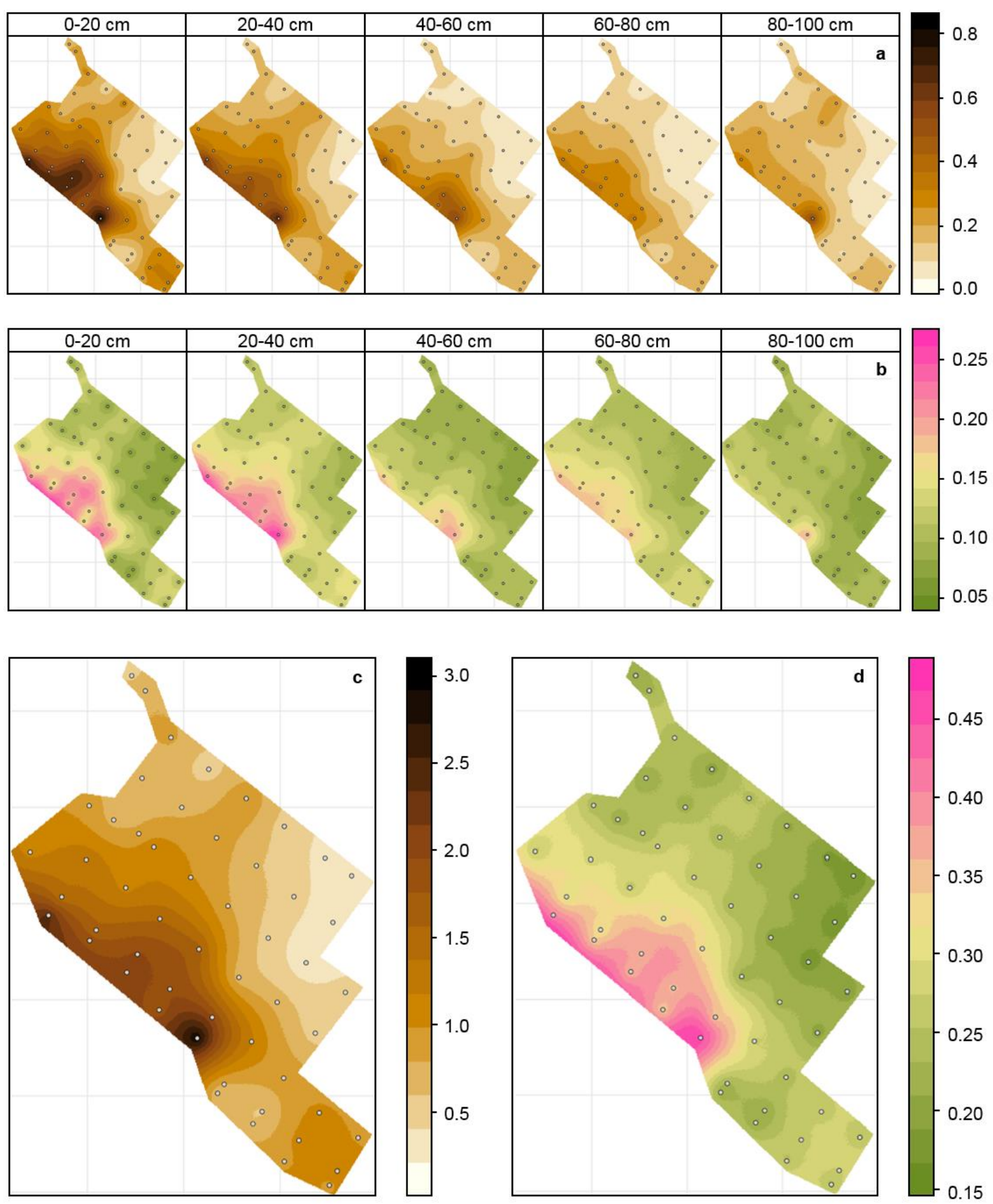

Fig. 5. Depth- $(0.2 \mathrm{~m})$ and profile-wise $(1.0 \mathrm{~m})$ maps of predicted Total Ca stocks $(\mathrm{kg}$ $\mathrm{m}^{-2}$ ) (a and $\mathrm{c}$, respectively) including the maps of the associated standard deviation $\left(\mathrm{kg} \mathrm{m}^{-2}\right)(\mathrm{b}$ and $\mathrm{d}$, respectively). 

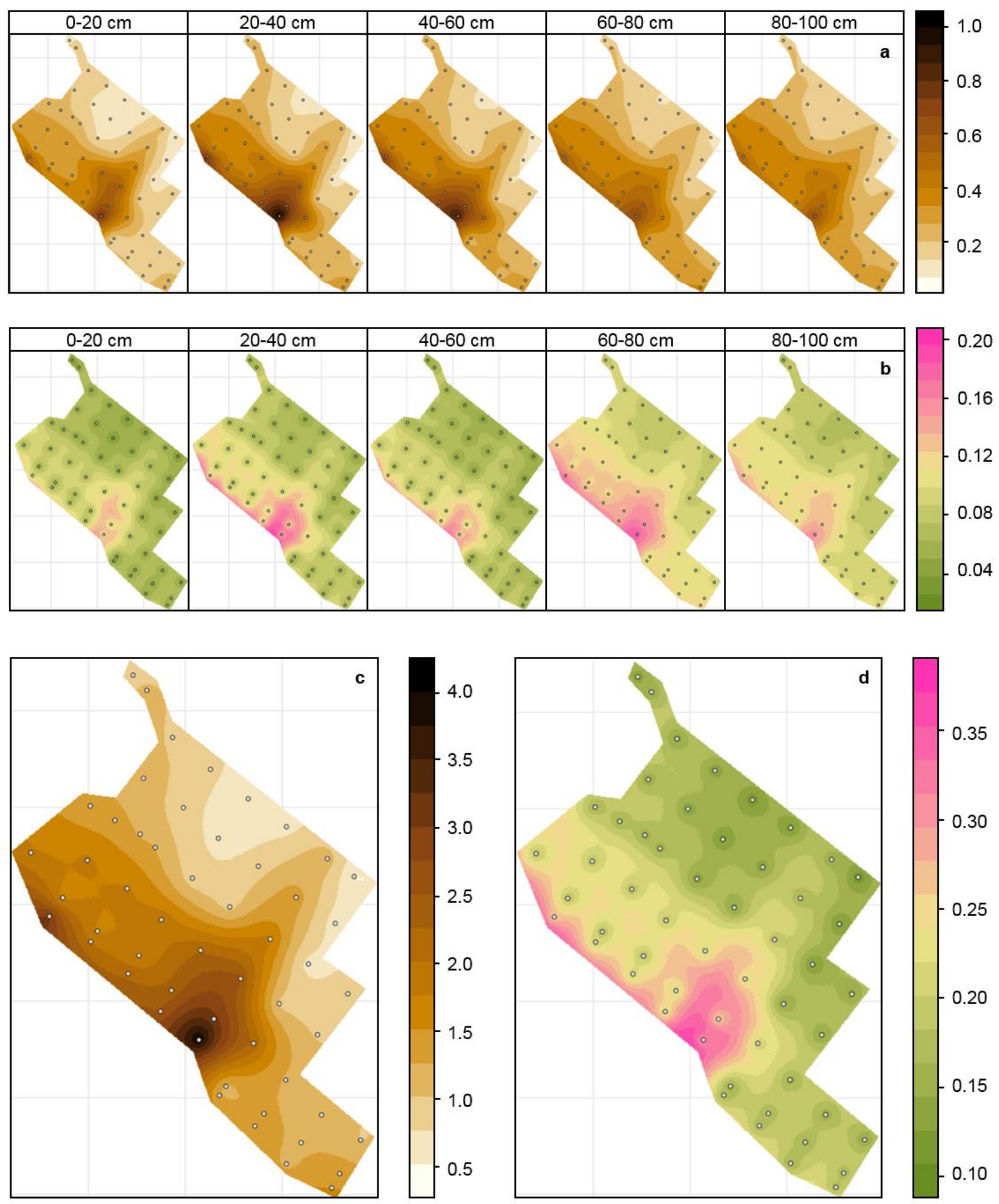

Fig. 6. Depth- $(0.2 \mathrm{~m})$ and profile-wise $(1.0 \mathrm{~m})$ maps of predicted Total $P$ stocks $(\mathrm{kg}$ $\mathrm{m}^{-2}$ ) (a and $\mathrm{c}$, respectively) including the maps of the associated standard deviation $\left(\mathrm{kg} \mathrm{m}^{-2}\right)$ (b and d, respectively).

\subsection{Probability of point-predictions to meet the pretic horizon criteria (pretic)}

The probability map of point-predictions to meet the pretic horizon criteria ( $p_{\text {pretic }}$ ) according to Total $\mathrm{C}$, Exchangeable $\mathrm{Ca}+\mathrm{Mg}$ and Extractable $\mathrm{P}$ is shown in Fig. 7. The pretic horizon criteria (and a cut-off at ppretic $\geq 0.9$ ) allowed us to clearly distinguish two main areas with nearly half of the sampling points located on each 
side. One area was located in the SW sector ( $4.2 \mathrm{ha})$ and exhibited the highest probability to find a pretic horizon (ppretic values close to 1), whereas the other area was located in the NE sector of the study area ( $5.2 \mathrm{ha})$ with the lowest probability to find a pretic horizon ( $p$ pretic values close to 0 ). The transition between these two main areas of either very high or very low ppretic was rather sharp.

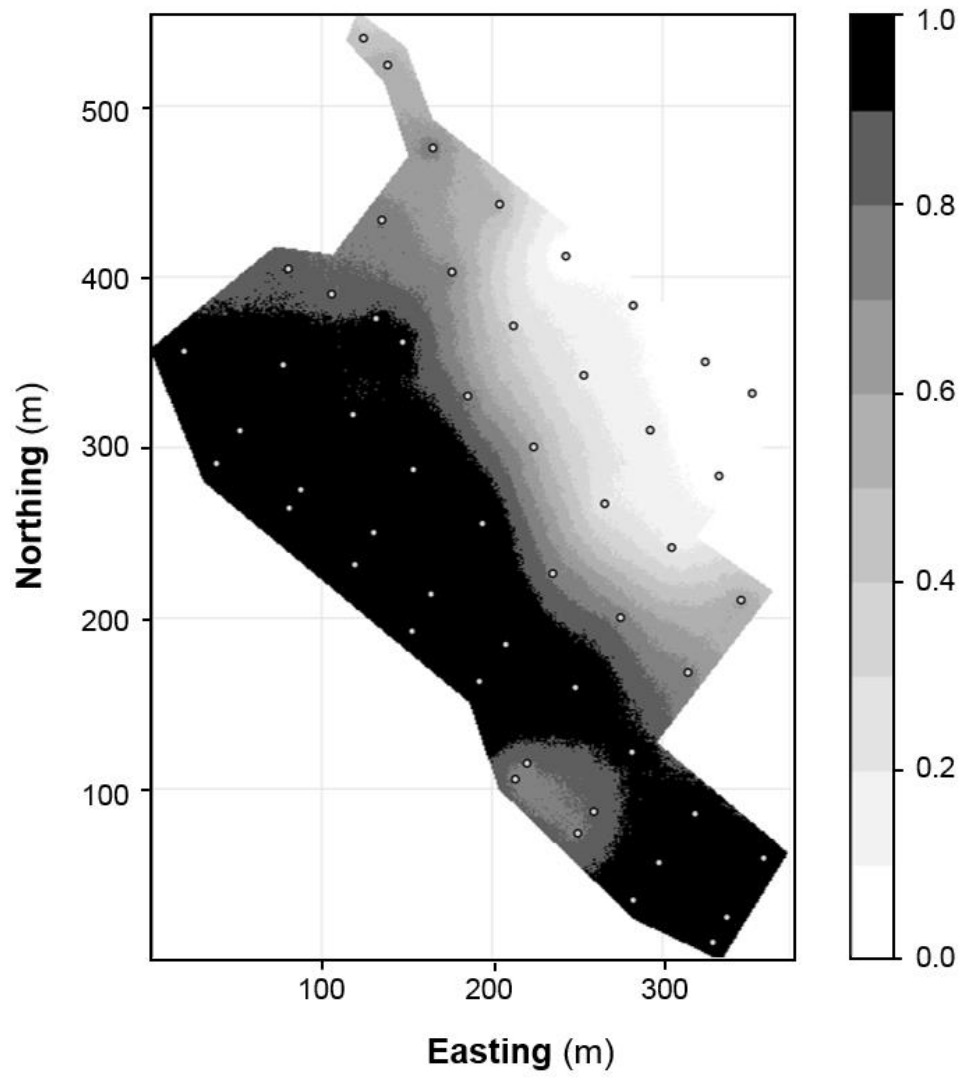

Fig. 7. Probability map of point-predictions to meet the pretic horizon criteria (ppretic) according Total $\mathrm{C}$, Exchangeable $\mathrm{Ca}+\mathrm{Mg}$ and Extractable $\mathrm{P}$. Soil properties were simulated separately and the lowest (most restrictive) probability was taken as the estimated pretic probability ( $p_{\text {pretic }}$ ). Values vary from 0 to 1 and a cut-off at $p_{\text {pretic }} \geq$ 0.9 was used to differentiate pretic from non-pretic areas.

\section{Discussion}

Depth- and profile-wise linear regression model parameters did not indicate a great importance of the chosen covariate (i.e. expected anthropic enrichment gradient) to explain the spatial variation of Total $C$ stocks (Table 1). Low $R^{2}$ values indicate low accuracy (how close a value is to the true value) and low precision (standard deviation to the true value). Nonetheless, the chosen covariate indicated a greater importance for Total Ca stocks and most importantly, Total P stocks (Table 1). Costa and Kern (1999) pointed out that high carbon turnover rates in the tropics likely hinders past interpretations. Therefore, Total $\mathrm{Ca}$ and Total $\mathrm{P}$ stocks are possibly better markers of the anthropic enrichment in ADE in contrast to Total $C$ stocks. Costa et al. (2013) suggested that phosphorus can be an important indicator and delimiter of anthropic areas due to high affinity to bind to iron and aluminium oxides in the soil.

Depth- and profile-wise maps of predicted Total $\mathrm{C}$, Total $\mathrm{Ca}$ and Total $\mathrm{P}$ stocks exhibited high spatial variation in our study area. Therefore, limited amount of soil 
samples selected on highly contrasting areas based on field observations (i.e. darkversus light-coloured soils and presence versus absence of archaeological remains) are likely to give an unrealistic estimation of the overall carbon and nutrients stocks in ADE. Costa and Kern (1999) reported that only the surface horizon exhibited anthropic enrichments. However, here we showed that enrichments can be observed even in deep soil layers. One patch in the SW sector exhibited the highest stocks for all three elements (Fig. 4 to Fig. 6). Given the sampling density limitation to capture the structure of the spatial variation in the short-scale $(<50 \mathrm{~m})$, the uncertainties of predictions are higher around this one patch with extreme values.

The probability map of point-predictions to meet the pretic horizon criteria (ppretic) indicated that the ppretic was higher in the SW sector (Fig. 7). Nonetheless, depthwise maps of predicted total stocks showed that the non-pretic area can also exhibit stocks as high as the pretic area (Fig. 4a to Fig. 6a). In this sense, we reinforce that limited soil sampling is unlikely to capture the complexity of the spatial variation of soil properties in ADE. Studies with extensive soil sampling (Fraser et al., 2011; Schmidt et al., 2014), suggested that the transition from ADE to the adjacent soil is characterized by a soil fertility continuum. In addition, Fraser et al. (2011) pointed out that ADE are sometimes subcategorized into Terra Preta and Terra Mulata. The term Terra Preta refers to the typical carbon- and nutrient-enriched soils with archaeological remains, whereas Terra Mulata refers to a less enriched soil with few or no evidence of archaeological remains. Nonetheless, both soil categories would differ from the adjacent soil. Costa et al (2013) reported that it was not possible to identify a specific geochemical signature for Terra Mulata. In our study, we did not find indications to support a subcategory within ADE (i.e. Terra Mulata) nor did we find a smooth transition between ADE and the adjacent soil. Here, we showed that the pretic horizon criteria (and a cut-off at ppretic $\geq 0.9$ ) allowed us to clearly differentiate two unambiguous areas with a sharp transition, rather than a smooth continuum, despite high spatial variation in our study area.

Depth-wise Total $\mathrm{C}$, Total $\mathrm{Ca}$ and Total $\mathrm{P}$ stocks in pretic and non-pretic areas are shown in Fig. 8. Overall, the predicted carbon and nutrients stocks were higher in the pretic area. However, the additional stocks in the pretic area (enrichment factor) varied per element and soil depth (Fig. 8). The overall Total C stock was $162.9 \mathrm{Mg}$ $\mathrm{ha}^{-1} \mathrm{~m}^{-1}$ in the pretic area and was on average only $14 \%$ larger than the non-pretic area. We used an average soil bulk density of $1.3 \mathrm{Mg} \mathrm{m}^{-3}$ to estimate the stocks in other studies and compare with our results. Overall, the range of carbon stocks reported for the soils of the Amazon basin is very broad. Moraes et al. (1995) reported an overall mean carbon stock of about $100 \mathrm{Mg} \mathrm{ha}^{-1} \mathrm{~m}^{-1}$ for soils in the Amazon basin, while Glaser et al. (2002) reported values in ADE as high as $500 \mathrm{Mg}$ $\mathrm{ha}^{-1} \mathrm{~m}^{-1}$. Lima et al. (2002) investigating $A$ horizons in a toposequence in the Amazon, reported carbon stocks from 54.7 to $134.9 \mathrm{Mg} \mathrm{ha}^{-1}$ in ADE and 6.3 to 35.4 $\mathrm{Mg} \mathrm{ha}^{-1}$ in the adjacent soil. In general, nutrient stocks in soils of the Amazon basin have been less investigated than carbon stocks. In our study, the overall Total $\mathrm{Ca}$ and Total $\mathrm{P}$ stocks were 14.2 and $19.0 \mathrm{Mg} \mathrm{ha}^{-1} \mathrm{~m}^{-1}$ in the pretic area as opposed to 6.6 and $11.0 \mathrm{Mg} \mathrm{ha}^{-1} \mathrm{~m}^{-1}$ in the non-pretic area. These values correspond to 2.1- and 1.7-fold larger stocks in the pretic area for Total $\mathrm{Ca}$ and Total $\mathrm{P}$ stocks, respectively. Costa et al. (2013) reported values corresponding to $2.8 \mathrm{Mg} \mathrm{ha}^{-1}$ and $2.3 \mathrm{Mg} \mathrm{ha}^{-1}$ for Total $\mathrm{Ca}$ and Total $\mathrm{P}$ stocks at $0-20 \mathrm{~cm}$, respectively. In contrast, the adjacent soil exhibited values corresponding to only 0.4 and $0.5 \mathrm{Mg} \mathrm{ha}^{-1}$ for Total $\mathrm{Ca}$ and Total $\mathrm{P}$ stocks at 0-20 cm, respectively. 


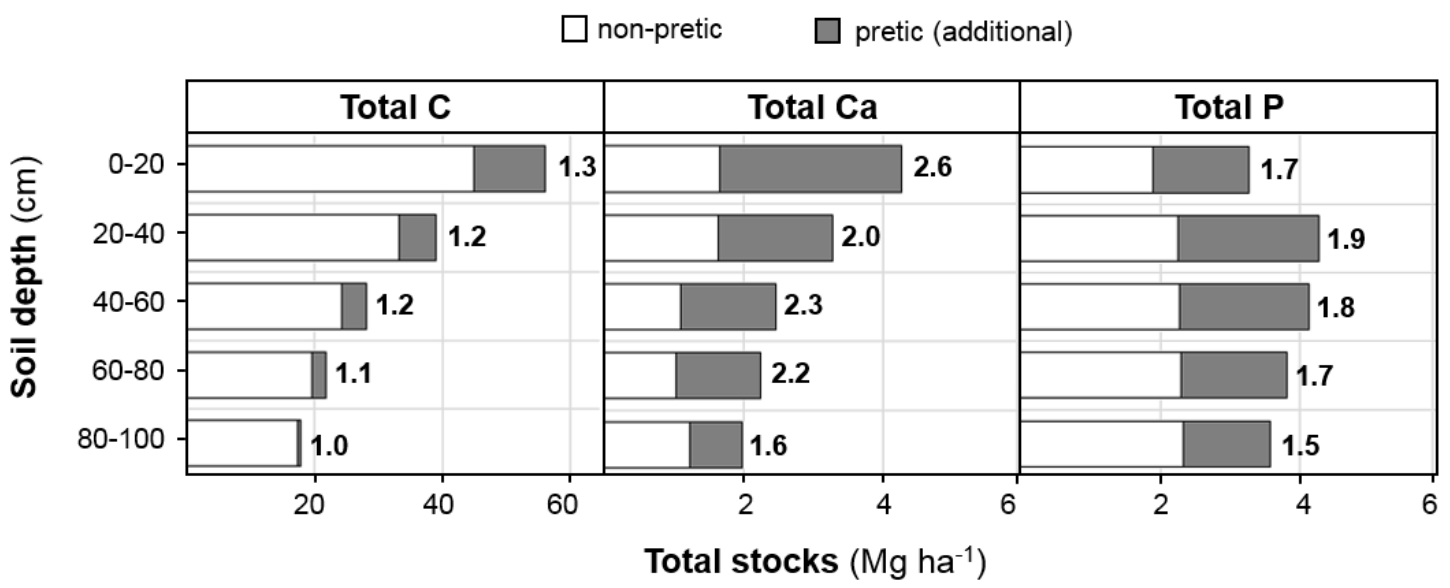

Fig. 8. Depth-wise Total $\mathrm{C}$, Total $\mathrm{Ca}$ and Total $\mathrm{P}$ stocks in pretic and non-pretic areas. The stocks in the pretic area are the sum of the stocks in the non-pretic area (empty bars) plus the additional stocks in the pretic area (filled bars). The enrichment factors per soil depth are shown on the left side of each bar.

Besides the commonly reported high carbon and nutrients contents in ADE, one of the most remarkable characteristics of ADE is the higher CEC when compared to the adjacent soils. Liang et al. (2006) reported a high correlation between CEC and the carbon content in ADE. In our study, the correlation between the CEC and the Total $C$ content was also higher in the pretic area $\left(R^{2}=0.82, p<0.05,125\right.$ soil samples) than the non-pretic area $\left(R^{2}=0.57, p<0.05,140\right.$ soil samples). Even though the Total $\mathrm{C}$ content decreased with depth, the ratio between CEC and the Total C content (CEC:C) increased with soil depth, most importantly in the pretic area (Fig. 9a). Data in Glaser et al. (2000) showed higher CEC:C in ADE when compared to the adjacent soil at surface horizons (0.33 against 0.08 in ADE and the adjacent soil at $0-10 \mathrm{~cm}$, respectively). Here, we showed that the CEC:C is even greater in deeper soil layers (Fig. 8a). Data in Oliveira et al. (2014) also showed higher CEC:C with increasing soil depth in ADE under different land use (0.44 in $A D E$ at $0-10 \mathrm{~cm}$ under corn and 2.46 in ADE at 100-130 cm under orchard). Even though the clay content increased with soil depth in our study area (Fig. 3), we did not observe differences in the soil texture between pretic and non-pretic areas (Supplementary Data). Therefore, the differences in CEC:C ratio between these areas may be attributed to carbon-related characteristics. Studies have shown that oxidation of black carbon (BC) is a key trait explaining high CEC in ADE (Glaser and Birk, 2012; Hiemstra et al., 2013; Liang et al., 2013; Novotny et al., 2007). Conceding that $\mathrm{ADE}$ is a model to sustainable agriculture in the tropics, higher CEC per unit of carbon is certainly a desirable characteristic to be reproduced.

There was a high significant correlation between Total $\mathrm{Ca}$ and Total $\mathrm{P}$ contents in the pretic area $\left(R^{2}=0.78, p<0.05,125\right.$ soil samples). Conversely, the correlation between Total $\mathrm{Ca}$ and Total $\mathrm{P}$ contents in the non-pretic area was close to zero and not significant $\left(R^{2}=0.03, p>0.05,140\right.$ samples) (Fig. 9b). This clearly indicates different sources and reaction pathways for these elements in pretic and non-pretic areas. Sato et al. (2009) investigating a chronosequence of ADE sites reported that biogenic calcium phosphate (i.e. bone-derived) disappeared after approximately 2000 years of ADE formation. Biogenic calcium phosphate transformations into more soluble fractions coincided with increased phosphorus adsorbed on soil oxides, 
organic phosphorus and occluded phosphorus. In addition, these authors reported that degradation of biogenic calcium phosphate occurred ten times faster than that of geogenic calcium phosphate (i.e. mineral-derived) under tropical conditions. Costa et al. (2013) also reported a high correlation between $\mathrm{Ca}$ and $\mathrm{P}$ values in ADE when compared to adjacent soils. In addition, these authors reported areas enriched in $P$ where no ceramic was found, which may indicate the location of disposal areas, particularly of animal origin (i.e. bones). For instance, the one patch in our study area where the highest stocks were found (Fig. 4 to Fig. 6) could have been a former waste disposal area (Costa et al., 2013; Schmidt et al., 2014). Studies commonly describe ADE as rich in ceramics and some studies even suggested that ceramics may be an important source of nutrients in ADE (Valente and Costa, 2017). However, ceramics fragments were totally absent in the majority (> 65\%) of the soil samples in our study area (Fuig. 2b). Therefore, effects of ceramics on enrichment of nutrients are likely to be of minor importance and extremely localized.
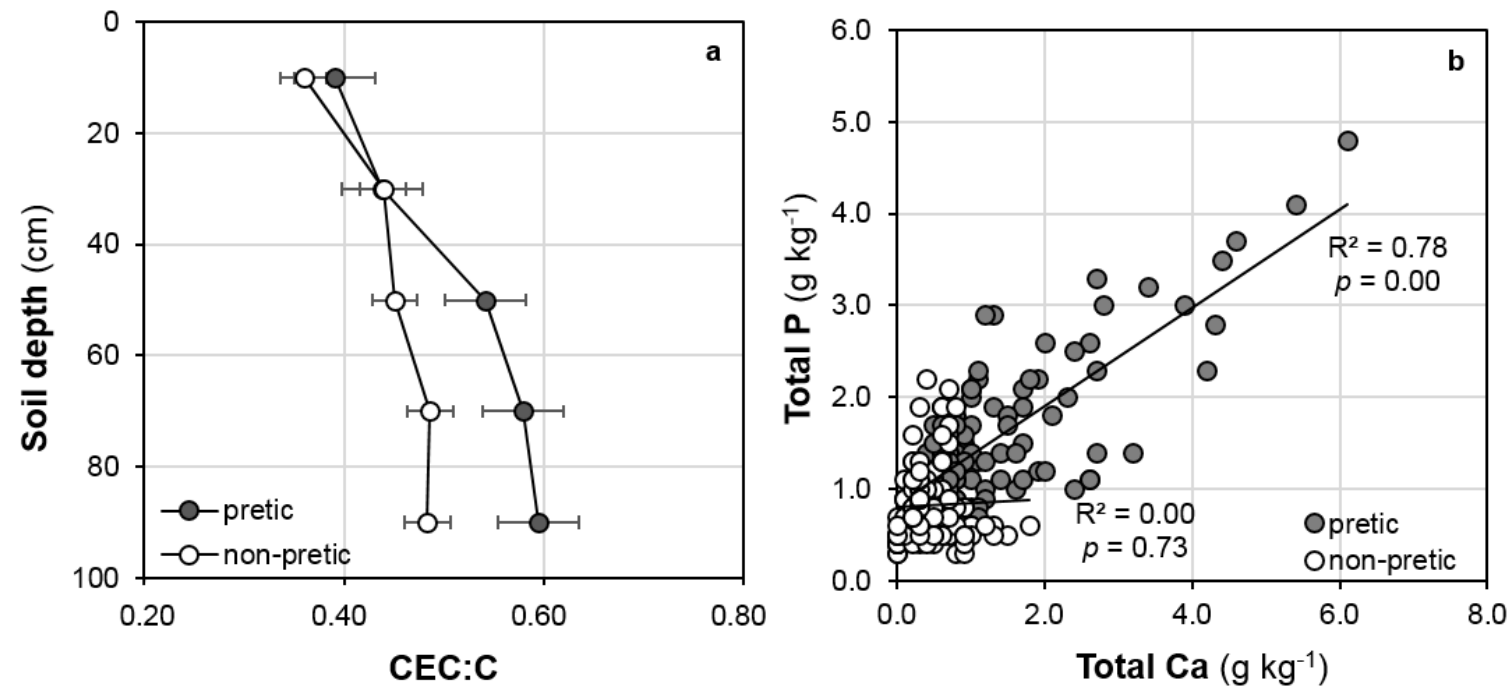

Fig. 9. (a) Depth-wise CEC (cmolc $\left.\mathrm{kg}^{-1}\right)$ per Total $\mathrm{C}$ content $\left(\mathrm{g} \mathrm{kg}^{-1}\right)$ (CEC:Total C). (b) Correlation between Total $\mathrm{Ca}$ and Total $\mathrm{P}$ contents in pretic (125 samples) and non-pretic areas (140 soil samples).

Interdisciplinary studies are highly recommended to understand the complexity of ADE (Kern et al., 2017). Despite decades of research in ADE, direct comparison of data between studies is hindered by different analytical approaches. Soil samples can be analysed by different methods to determine either exchangeable or total contents. It is important to note that carbon stocks are commonly estimated with carbon content determined by the Walkley-Black (WB) method (Walkley and Black, 1934). However, the reliability of this method to account for BC has been questioned (Knicker et al., 2007) since the resistance of BC to sodium dichromate oxidation and its recovery is dependent on BC intrinsic level of oxidation and methodological reaction conditions (Hardy and Dufey, 2017). Therefore, if $B C$ is of great importance in ADE (Glaser, 2007; Glaser et al., 2001), then the WB method is unlikely to provide a realistic estimation of the carbon content in ADE or any other soil expected to be enriched in BC. Here, we determined Total $\mathrm{C}$ by elemental analysis to avoid underestimation of the carbon content.

It is possible that several mechanisms are simultaneously acting to explain the striking characteristics of ADE. For carbon, it is worth to note that Total $\mathrm{C}$ determined 
by elemental analysis accounts for carbon of different origins and different turnover rates. On the one hand, part of the carbon content likely exhibits a high turnover rate that hinders past interpretations (Costa and Kern, 1999). On the other hand, BC found in ADE is expected to remain in the soil for longer periods due to its inherent stability (Glaser, 2007; Haumaier and Zech, 1995; Novotny et al., 2007). In this sense, specific assessment of the $\mathrm{BC}$ content may contribute to better interpretations of the carbon content in ADE. For calcium, higher CEC derived from BC oxidation likely enhances $\mathrm{Ca}$ adsorption (Archanjo et al., 2014). For phosphorus, it has been suggested that adsorption of phosphate $\left(\mathrm{PO}_{4}{ }^{-3}\right)$ and $\mathrm{SOM}$ to soil oxides may inhibit their further growth and polymerization (Eusterhues et al., 2008; Fukushi and Sato, 2005) and are likely to be the cause of nano-sized particles with high surface area in soils (Hiemstra et al., 2010). A higher surface area likely increases the amount of adsorbed SOM that can be of $\mathrm{BC}$ and non-BC origin. However, since $\mathrm{PO}_{4}{ }^{-3}$ may compete with SOM for adsorption sites on the surface of oxides (Antelo et al., 2007; Weng et al., 2008), the trade-offs are poorly understood. Therefore, further research is still needed to better understand the relative contribution of these different mechanisms in order to reproduce ADE remarkable characteristics that are desirable for sustainable agriculture.

\section{Conclusions}

The use of the pretic horizon criteria in combination with a cut-off at at $p_{\text {pretic }} \geq 0.9$ permits an unambiguous identification of distinctive areas in ADE. In contrast to previous ADE studies, the presented method generates a sharp transition between two areas rather than a smooth continuum. Total Ca stocks and especially Total $P$ stocks were better markers of anthropic enrichment in ADE than Total C stocks. Depth- and profile-wise linear regression model parameters indicated a greater importance of the chosen environmental covariate (i.e. expected anthropic enrichment gradient) to explain the spatial variation of Total $\mathrm{Ca}$ and Total $\mathrm{P}$ stocks than Total $\mathrm{C}$ stocks. The overall Total $\mathrm{Ca}$ and Total $\mathrm{P}$ stocks were twice as large in the pretic area when compared to the non-pretic area. In addition, there was a high significant correlation between Total $\mathrm{Ca}$ and Total $\mathrm{P}$ contents in the pretic area, whereas no correlation was found in the non-pretic area. This clearly indicates different sources and reaction pathways for these elements in pretic and non-pretic areas.

\section{Acknowledgments}

We acknowledge the contribution of G.B.M. Heuvelink and two anonymous reviewers for the improvement of our manuscript. This work was done under the scope of the Terra Preta Program and funded by the Interdisciplinary Research and Education Fund (INREF) of Wageningen University and Research (WUR) and the Brazilian Agricultural Research Corporation (Embrapa).

\section{References}

Antelo, J., Arce, F., Avena, M., Fiol, S., López, R., Macías, F., 2007. Adsorption of a soil humic acid at the surface of goethite and its competitive interaction with phosphate. Geoderma 138, 12-19. https://doi.org/10.1016/j.geoderma.2006.10.011 
Archanjo, B.S., Araujo, J.R., Silva, A.M., Capaz, R.B., Falcão, N.P.S., Jorio, A., Achete, C.A., 2014. Chemical analysis and molecular models for calcium-oxygencarbon interactions in black carbon found in fertile amazonian anthrosoils. Environ. Sci. Technol. 48, 7445-7452. https://doi.org/10.1021/es501046b

Browne-Ribeiro, A.T., 2016. A Fine-Grained Analysis of Terra Preta Formation, in: Contreas, D.A. (Ed.), The Archaeology of Human-Environment Interactions. Routledge, New York, pp. 165-194.

Costa, J.A., Costa, M.L. da, Kern, D.C., 2013. Analysis of the spatial distribution of geochemical signatures for the identification of prehistoric settlement patterns in ADE and TMA sites in the lower Amazon Basin. J. Archaeol. Sci. 40, 2771-2782. https://doi.org/10.1016/j.jas.2012.12.027

Costa, M.L. da;, Kern, D.C., 1999. Geochemical signatures of tropical soils with archaeological black earth in the Amazon, Brazil. J. Geochemical Explor. 66, 369385. https://doi.org/10.1016/S0375-6742(99)00038-2

Embrapa, 2017. Manual de métodos de analise de solo, Embrapa Solos. https://doi.org/1517-2627

Eusterhues, K., Wagner, F.E., Ha, W., Hanzlik, M., Knicker, H., Totsche, K.U., Ko, I., Schwertmann, U., 2008. Characterization of Ferrihydrite-Soil Organic Matter Coprecipitates by X-ray Diffraction and Mössbauer Spectroscopy Characterization of Ferrihydrite-Soil Organic Matter Coprecipitates by X-ray Diffraction and Mo Spectroscopy. Environ. Sci. Technol. 42, 7891-7897. https://doi.org/10.1021/es800881w

Fraser, J.A., Leach, M., Fairhead, J., 2014. Anthropogenic Dark Earths in the Landscapes of Upper Guinea, West Africa: Intentional or Inevitable? Ann. Assoc. Am. Geogr. 104, 1222-1238. https://doi.org/10.1080/00045608.2014.941735

Fraser, J.A., Teixeira, W.G., Falcão, N.P.S., Woods, W., Lehmann, J., Junqueira, A.B., 2011. Anthropogenic soils in the Central Amazon: from categories to a continuum. Area 43, 264-273. https://doi.org/10.1111/j.1475-4762.2011.00999.x

Fukushi, K., Sato, T., 2005. Using a surface complexation model to predict the mature and stability of nanoparticles. Environ. Sci. Technol. 39, 1250-1256. https://doi.org/10.1021/es0491984

Glaser, B., 2007. Prehistorically modified soils of central Amazonia: a model for sustainable agriculture in the twenty-first century. Philos. Trans. R. Soc. Lond. B. Biol. Sci. 362, 187-196. https://doi.org/10.1098/rstb.2006.1978

Glaser, B., Balashov, E., Haumaier, L., Guggenberger, G., Zech, W., 2000. Black carbon in density fractions of anthropogenic soils of the Brazilian Amazon region. Org. Geochem. 31, 669-678. https://doi.org/10.1016/S0146-6380(00)00044-9

Glaser, B., Birk, J.J., 2012. State of the scientific knowledge on properties and 
genesis of Anthropogenic Dark Earths in Central Amazonia (terra preta de Índio). Geochim. Cosmochim. Acta 82, 39-51. https://doi.org/10.1016/j.gca.2010.11.029 Glaser, B., Haumaier, L., Guggenberger, G., Zech, W., 2001. The "Terra Preta" phenomenon: a model for sustainable agriculture in the humid tropics. Naturwissenschaften 88, 37-41. https://doi.org/10.1007/s001140000193

Glaser, B., Lehmann, J., Zech, W., 2002. Ameliorating physical and chemical properties of highly weathered soils in the tropics with charcoal - a review. Biol. Fertil. Soils 35, 219-230. https://doi.org/10.1007/s00374-002-0466-4

Goovaerts, P., 1997. Geostatistics for Natural Resources Evaluation, Oxford University Press. New York.

Hardy, B., Dufey, J.E., 2017. The resistance of centennial soil charcoal to the "Walkley-Black" oxidation. Geoderma 303, 37-43. https://doi.org/10.1016/j.geoderma.2017.05.001

Hastie, T., Tibshirani, R., Friedman, J., 2009. The Elements of Statistical Learning, second. ed. Springer, New York. https://doi.org/10.1007/b94608

Haumaier, L., Zech, W., 1995. Black carbon-possible source of highly aromatic components of soil humic acids. Org. Geochem. 23, 191-196. https://doi.org/10.1016/0146-6380(95)00003-W

Heuvelink, G.B.M., Burrough, P.A., Stein, A., 1989. Propagation of errors in spatial modelling with GIS. Int. J. Geogr. Inf. Syst. 3, 303-322. https://doi.org/10.1080/02693798908941518

Heuvelink, G.B.M., Webster, R., 2001. Modelling soil variation: past, present, and future. Geoderma 100, 269-301. https://doi.org/10.1016/S0016-7061(01)00025-8

Hiemstra, T., Antelo, J., van Rotterdam, a. M.D. (Debby), van Riemsdijk, W.H., 2010. Nanoparticles in natural systems II: The natural oxide fraction at interaction with natural organic matter and phosphate. Geochim. Cosmochim. Acta 74, 59-69. https://doi.org/10.1016/j.gca.2009.10.019

Hiemstra, T., Mia, S., Duhaut, P.B., Molleman, B., 2013. Natural and pyrogenic humic acids at goethite and natural oxide surfaces interacting with phosphate. Environ. Sci. Technol. 47, 9182-9189. https://doi.org/10.1021/es400997n

IUSS Working Group WRB, 2015. World reference base for soil resources 2014, update 2015. International soil classification system for naming soils and creating legends for soil maps, World Soil Resources Reports No. 106. FAO, Rome. https://doi.org/10.1017/S0014479706394902

Kämpf, N., Woods, W., Sombroek, W., Kern, D.C., Cunha, T.J.F., 2003. Classification of Amazonian Dark Earths and other ancient anthropic soils, in:

Lehmann, J., Kern, D.C., Glaser, B., Woods, W. (Eds.), Amazonian Dark Earths: Origin, Properties, Management. Springer, Dordrecht, pp. 77-102. 
Kern, D.C., Costa, J.A., Silveira, M.I. da, Oliveira, E.R. de, Frazão, F.J.L., Berredo, J.F., Costa, M.L. da, Kämpf, N., 2015. Pedo-Geochemical Signatures of Archeological Sites in the Tapirapé-Aquiri National Forest in Marabá, Amazonia, Brazil. Geoarchaeology 30, 430-451. https://doi.org/10.1002/gea.21528

Kern, D.C., Lima, H.P., Costa, J.A. da, Lima, H.V. de, Browne-Ribeiro, A.T., Moraes, B.M., Kämpf, N., 2017. Terras pretas: Approaches to formation processes in a new paradigm. Geoarchaeology 32, 694-706. https://doi.org/10.1002/gea.21647

Knicker, H., Müller, P., Hilscher, A., 2007. How useful is chemical oxidation with dichromate for the determination of "Black Carbon" in fire-affected soils? Geoderma 142, 178-196. https://doi.org/10.1016/j.geoderma.2007.08.010

Kyriakidis, P.C., Journel, A.G., 1999. Geostatistical space-time models: A review. Math. Geol. 31, 651-684. https://doi.org/10.1023/A:1007528426688

Lark, R.M., Webster, R., 2006. Geostatistical mapping of geomorphic variables in the presence of trend. Earth Surf. Process. Landforms 31, 862-874. https://doi.org/10.1002/esp.1296

Liang, B., Lehmann, J., Solomon, D., Kinyangi, J., Grossman, J.M., O’Neill, B., Skjemstad, J.O., Thies, J.E., Luizão, F.J., Petersen, J., Neves, E.G., 2006. Black Carbon Increases Cation Exchange Capacity in Soils. Soil Sci. Soc. Am. J. 70, 1719. https://doi.org/10.2136/sssaj2005.0383

Liang, B., Wang, C., Solomon, D., Kinyangi, J., Luizão, F.J., Wirick, S., Skjemstad, J.O., Lehmann, J., 2013. Oxidation is Key for Black Carbon Surface Functionality and Nutrient Retention in Amazon Anthrosols. Br. J. Environ. Clim. Chang. 3, 9-23. https://doi.org/10.9734/BJECC/2013/2267

Lima, H.N., Schaefer, C.E.R., Mello, J.W. V., Gilkes, R.J., Ker, J.C., 2002. Pedogenesis and pre-Colombian land use of "Terra Preta Anthrosols" ("Indian black earth") of Western Amazonia. Geoderma 110, 1-17. https://doi.org/10.1016/S00167061(02)00141-6

Macedo, A.G.S., 2012. Caracterização e variação temporal da solução do solo em argissolo amarelo com horizonte A moderado e A antrópico (Terra Preta de Índio) no município de Iranduba - AM (MSc Thesis). Federal University of Amazonas.

Macedo, R.S., Teixeira, W.G., Corrêa, M.M., Martins, G.C., Vidal-Torrado, P., 2017. Pedogenetic processes in anthrosols with pretic horizon (Amazonian Dark Earth) in Central Amazon, Brazil. PLoS One 12, 1-19. https://doi.org/10.1371/journal.pone.0178038

Moraes, J.L., Cerri, C.C., Melillo, J.M., Kicklighter, D., Neill, C., Skole, D.L., Steudler, P.A., 1995. Soil carbon stocks of the Brazilian Amazon basin. Soil Sci. Soc. Am. J. 59, 244-247. https://doi.org/10.2136/sssaj1995.03615995005900010038x

Neves, E.G., Petersen, J.B., Bartone, R.N., Silva, C.A. da, 2003. Historical and Socio-cultural Origins of Amazonian Dark Earth, in: Lehmann, J., Kern, D.C., Glaser, 
B., Woods, W. (Eds.), Amazonian Dark Earths: Origin, Properties, Management. Springer, Dordrecht, pp. 29-50. https://doi.org/10.1097/00010694-200503000-00009 Neves Júnior, A.F., 2008. Qualidade física de solos com horizonte antrópico (Terra Preta de Índio) na Amazônia Central (PhD thesis). University of São Paulo.

Novotny, E.H., Deazevedo, E.R., Bonagamba, T.J., Cunha, T.J.F., Madari, B.E., Benites, V.D.M., Hayes, M.H.B., 2007. Studies of the compositions of humic acids from Amazonian Dark Earth soils. Environ. Sci. Technol. 41, 400-405. https://doi.org/10.1021/es060941x

Oliveira, I.A. de, Marques Júnior, J., Campos, M.C.C., Aquino, R.E. de, Siqueira, D.S., Freitas, L. De, 2014. Spacial Variability and Sampling Density of Chemical Attributes in Archaeological Black Earth and Native Forest Soil in Manicoré, AM. Floresta 44, 735-746. https://doi.org/10.5380/rf.v44i4.29988

Oliver, M.A., Webster, R., 2014. A tutorial guide to geostatistics: Computing and modelling variograms and kriging. Catena 113, 56-69. https://doi.org/10.1016/j.catena.2013.09.006

Pebesma, E.J., 2004. Multivariable geostatistics in S: The gstat package. Comput. Geosci. 30, 683-691. https://doi.org/10.1016/j.cageo.2004.03.012

Pettitt, A.N., McBratney, A.B., 1993. Sampling Designs for Estimating Spatial Variance. J. R. Stat. Soc. 42, 185-209. https://doi.org/10.2307/2347420

Samuel-Rosa, A., Heuvelink, G.B.M., Vasques, G.M., Anjos, L.H.C., 2015. Do more detailed environmental covariates deliver more accurate soil maps? Geoderma 243244, 214-227. https://doi.org/10.1016/j.geoderma.2014.12.017

Sato, S., Neves, E.G., Solomon, D., Liang, B., Lehmann, J., 2009. Biogenic calcium phosphate transformation in soils over millennial time scales. J. Soils Sediments 9, 194-205. https://doi.org/10.1007/s11368-009-0082-0

Schmidt, M.J., Py-Daniel, A.R., Moraes, C. de P., Valle, R.B.M., Caromano, C.F., Teixeira, W.G., Barbosa, C.A., Fonseca, J.A., Magalhães, M.P., Santos, D.S. do C., Silva, R. da S. e, Guapindaia, V.L., Moraes, B., Lima, H.P., Neves, E.G., Heckenberger, M.J., 2014. Dark earths and the human built landscape in Amazonia: a widespread pattern of anthrosol formation. J. Archaeol. Sci. 42, 152-165. https://doi.org/10.1016/j.jas.2013.11.002

Sombroek, W.G., 1966. Amazon Soils (PhD thesis). Wageningen University.

Song, X.-D., Brus, D.J., Liu, F., Li, D.-C., Zhao, Y.-G., Yang, J.-L., Zhang, G.-L., 2016. Mapping soil organic carbon content by geographically weighted regression: $A$ case study in the Heihe River Basin, China. Geoderma 261, 11-22. https://doi.org/10.1016/j.geoderma.2015.06.024

Valente, G.J.S.S., Costa, M.L., 2017. Fertility and desorption capacity of Anthrosols (Archaeological Dark Earth - ADE) in the Amazon: The role of the ceramic fragments (sherds). Appl. Clay Sci. 138, 131-138. https://doi.org/10.1016/j.clay.2017.01.007 
Walkley, A., Black, I.A., 1934. An examination of the degtjareff method for determining soil organic matter, and a proposed modification of the chromic acid titration method. Soil Sci. https://doi.org/10.1097/00010694-193401000-00003

Webster, R., Oliver, M.A., 2007. Geostatistics for Environmental Scientists, second. ed. John Wiley \& Sons. https://doi.org/10.2136/vzj2002.0321

Weng, L., Riemsdijk, W.H. Van, Hiemstra, T., Quality, S., 2008. Humic Nanoparticles at the Oxide - Water Interface : Interactions with Phosphate Ion Adsorption. Environ. Sci. Technol 42, 8747-8752. 